\title{
Field Operations as Information Warfare and Operationalisation of Theory
}

\begin{abstract}
This chapter touches on concepts of information warfare, for example COIN-theory. Field theory as information warfare is the main topic. The purpose is to frame the field theory as a valid example of both method and theory regarding information warfare. This is especially important as a lot of the practice regarding information warfare is not anchored in a social theory but mostly in a best practice way of acting. That is all well but a theory provides a wider range of generalising and thus options of free-thinking.
\end{abstract}

Keywords Information warfare $\cdot$ COIN $\cdot$ Field theory

InfOps are mainly associated with guarding access to one's own information, but InfOps are also concerned with controlling the opposition's access to information. ${ }^{1}$ It is essentially the process of disinformation or denying information. The term InfOps is comparatively wide ranging and can involve operations that are not necessarily conducted during times of crisis or war. Information warfare is conducted with the aim of influencing an area suffering from war, crisis or other violent circumstances. Can the application of field theory therefore be said to constitute information operations? It must be admitted that it is an unorthodox

${ }^{1}$ Dictionary of Military Terms (1999), London.

(C) The Author(s) 2017

H. Gunneriusson, Bordieuan Field Theory as an Instrument for Military Operational Analysis, New Security Challenges, DOI 10.1007/978-3-319-65352-5_4 
form of warfare. The answer is affirmative, with the finesse that the enemy does not need to be completely identified but just by his methods and goals. The aim is to attack a critical vulnerability of the enemy by altering the social, political and economic reference system. In a paraphrase of a famous saying by Mao, one might say that it is a question of changing the water in which the fish are swimming. The critical vulnerability of the enemy is his political legitimacy in the mission area. The attack is conducted by changing the conditions of the field so that even unidentified political actors may also find themselves under attack. If the vulnerable point is attacked, the enemy's centre of gravity will have to be adjusted accordingly. For this approach to be effective, the actor must be a genuine political actor, an actor interested in political gain. If the actor has no political ambitions-perhaps in the case of organised crime for financial gain - then there is also no reason not to countermine the actor's position as a player on the field. However, it is important that there is a general perception that the actor is not a political actor. It is the judgement of the field, not that of the actor, that determines whether an actor is political or not. ${ }^{2}$ It is worth stressing the importance of qualitative knowledge of the actors on the field, in the same way that knowledge of the field's own structure is key information.

A field theoretical approach to operations should strive to give the enemy information of a type that is not disinformative. As it is a long process, it is important to not undermine the trust in the process with disinformation. The information presented should fit with the stated aim of influencing the actor to change his strategy. It involves information in the form of action rather than words, to clearly show the disadvantages of a strategy of violence by confronting him with a well-armed and wellequipped military force. It is also important to clearly show the alternative strategies that are possible. The latter should be combined with making it obvious that the positions of non-violent actors will be greatly enhanced, whatever their political standpoint. In this way, it will become clear to all that those with a non-violent political agenda will experience a considerable enhancement of their power, while the increase in power for the actors using violent means will be obstructed or will suffer a reverse. It is thus important to inform the enemy in the correct manner. As this will change the distribution of power on the field, one might see different and new

\footnotetext{
${ }^{2}$ However, the field can be influenced to form a certain opinion of a particular actor.
} 
avenues of action being taken which can only be determined by empirical observation rather than theoretical laws. One can, for example, see that factions try to push a more civil branch of action while still not completely abandoning the capacity to violence in another respect, in effect a possible case of lip service. One might also see that complicity might result in armed groups of a faction (whatever its constitution) might turn on what they perceive as collaborators. In the latter case, the capacity of violence by our own forces must not be dismissed as unnecessary.

Nevertheless, field theory information efforts have clear strategic implications, at least if by strategy one means creating an overall plan and materially providing sufficiently for the operational level to ensure that information can be communicated. It will require information and reconnaissance resources over and above normal levels if a field theory approach is to be more than just a shot in the dark. Information has been stated to be the key to irregular warfare, something which hardly can be denied. ${ }^{3}$ One can because of that clearly see the advantages of using a perspective as Field theory-which bases its foundation on information-as an operational COIN-approach.

Political activity is a manifestation of the will to acquire power through the accumulation of capital in the political field. By reading off the rules of the field, a range of measures can be instigated against various actors on the field to influence them to more or less voluntarily change their operational strategy. How this will be achieved is an empirical question and one that does not lend itself to theorising; all fields are unique and must be treated accordingly. It is a question partly of the interests and competence of the actors, and partly of the range of resources at the disposal of the international force. The DIME approach is one of many methods used to structure the various arenas used for an operation. ${ }^{4}$ This model can be useful in certain situations, but is far too general in most cases to be of interest for our purposes here. There are a number of possible measures of symbolic nature that actors in the political field in the operations may find attractive. Provided that the actors (collectively or individually) forego the use of violence as a political means, a range of offers can be made in return. These offers must be made clearly and abundantly to the actors

\footnotetext{
${ }^{3}$ Kalyvas (2009, p. 174), also quoting Eckstein (1965, p. 158).

${ }^{4}$ The acronym has later expanded to DIMEFIL (Diplomatic, Information, Military, Economic, Financial, Intelligence and Law Enforcement). Headquarters Department of the Army, p. 1.
} 
who are already positioned on the left side of the field. They must at no time be seen as a reward to the actors on the right side of the field. The maintenance of a strategy of violence on the right side of the field must be met with one of force until the strategy is clearly abandoned in favour of one that fits on the left side of the field. Only using force is the simple coercive approach. True, it is part of the structuring of the social field, but more restructuring of the field must be made-open up new attractive avenues of action for both actors who are benevolent but also others. It is important that the opportunity to switch strategy is always available and is actively encouraged. ${ }^{5}$

Examples of incentives to change strategy:

- Positions in public administration-dependent on competence and interest. Make them dependent.

- Consultation with actors on legislation-in line with a stated political agenda. Draw them in.

- Building up infrastructure-investment, priority, naming of installations (e.g. bridges, road systems and infrastructure for telecommunications). Hearts and minds.

- Building and siting of schools-for example specific home areas can be given priority. One can discredit as well as credit with tactical help.

- Alternative job opportunities - guaranteed employment for former militia. If Maslow's pyramid of needs is important in the case, then this will have effect.

The above are but a few examples of the incentives that might be offered to get actors to change their strategies, it is no way everything that can be done. It is important to read the actors and their priorities correctly; they maybe have no interest at all in job opportunities, but for example may well have an agenda for legislation. For instance, proposed legislation may be submitted to them for their consideration or they may even be

\footnotetext{
${ }^{5}$ The action taken by the USA against Iraq's Sunni leaders may be seen as a variation on this theme. They can always participate and influence the political process-influence developments - if they want to. The problem is that they will never acquire any real power when other ethnic groups make up $80 \%$ of the population. In this particular situation, the USA should have found alternative solutions to the problem by making the Sunni Muslims feel that they were part of the process.
} 
asked to take part in dialogue for the formulating of that legislation. For other groups, the most important thing may be securing an income for their members under safer conditions; this may be all the incentive necessary. Furthermore, many projects bear symbolic values far beyond the practical value the project brings. "Roads ain't roads", as David Kilcullen expresses it. ${ }^{6}$ They can signal an ambition of increased presence, military or other, it signals long-term commitment and ambitions.

The field theory approach aims at getting the actors to adopt strategies in line with the conditions that one has set for the field; they must be made to see that actors with non-violent strategies quickly acquire power and influence in society-in contrast to those who espouse violence. It is important to work to suppress violence and simultaneously actively promote the actors who support a non-violent political process. Doing this will tilt the power balance on the political social field in a direction wanted. The tools available for promoting these actors may come from within one's own organisation or from other organisations. Non-profit organisations are also actors on the field, regardless of whether or not they are working alongside the military force. The problem is that independent organisations have their own agendas different from that of the military force. It is also often the case that an NGO will lose respect in the area of operations if it works with the military force. It is often sufficient for NGO representatives to merely be afraid that this will happen, for cooperation to worsen. This, however, is something that needs to be addressed from case to case as it is an entirely empirical question.

Quantitative basic facts, used for positioning the actors, can over time be complemented with data that may not appear to have anything to do with power on the field, facts that may seem trivial. For example, details of choice of brand of cigarettes may be of interest. If it is seen that certain brands are consumed in great quantities or not at all by certain groups without any reasonable explanation, then one might have found something interesting. If a particular group smokes only a certain brand of cigarette this may point to smuggling activity which in its turn drives the informal economy.

${ }^{6}$ Kilcullen (2009, p. 108). 
How can field theory be operationalised? How does one decide where actors are positioned within the field? There is a choice of the two general methods of analysis, either qualitative or quantitative. First is something about the quantitative method. A special software application programme has been produced for quantitative analysis, and it is well known among those who make correspondence analyses. The method has been mentioned above and is called multiple correspondence analysis (MCA). In short, the process involves gathering a large amount of empirical data, regardless of whether or not it initially appears useful for defining the actors on the field. The information may include patterns of behaviour, social networks, consumer habits, economy, local political issues, what the different parts of society are focused on, etc. The results of this information gathering will then be processed to provide an empirical definition of the groups. Certain values or habits for the various actors may come to light that have not previously been noticed. Some information may be of the type that affords the actors prestige, respect, the opportunity to exercise power, access to various arenas such as the media, religious circles. All these factors are then processed, and an overall positioning of the actors within the field is then produced. An actor's position on the horizontal axis will be wholly dependent on his readiness or otherwise to use violence.

The second method involves a qualitative approach. As a result of observations made, the various actors are then positioned where one believes they fit on the field. This method may appear less reliable, but fulfils its purpose. The quantitative method relies on adopting the right parameters; the qualitative picture is based on an overall impression gained by studying and interacting on the field. ${ }^{7}$ What is appropriate is to a high degree dependent on a qualitative consideration of the analysis results. The quantitative method can be used at the strategic level where it is easier to gain an overview, because there often is a larger amount of incoming data than one can deal with. At the strategic level, the analysis can be used to accurately gauge which resources will be required at the operational level to enable successful accomplishment of the tasks identified by field theory analysis. The qualitative method can be used to advantage at the operational level, where one is better able to feel the

\footnotetext{
${ }^{7}$ Correspondence analysis assumes a certain familiarity with the use of software, but courses are available: http://www.skeptron.ilu.uu.se/broady/sec/k-kor04.htm [Visited $170509]$.
} 
pulse of the field on the ground-it is at this level that field theory has most potential. In the end, the need to gather information will lead to a demand for certain capabilities at the tactical level, even if the analysis is not conducted at that level. With the quantitative method, one gets a numerical value, with decimals. There is no reason to believe that the quantitative result is more valid than a qualitative one, as there are often qualitative decisions behind the quantitative ones. For example, what should an attack constitute to generate a number in the matrix and so on. With the qualitative method, you get an analysis which you have to decide on in terms of yes/no, do/don't. The lack of numbers might superficially seem a less reliable method, but it is all determined by the reliability of those doing the research, not the method itself. A decision about a yes or a no is often what you need in a given situation, no more, no less. Therefore, the qualitative method is sufficient as a method for decision-making.

Field theory sets great demands on intelligence work, but at the same time, it has been made easier with the advent of new technology. Field theory will carry with it its own genre of HUMINT. ${ }^{8}$ Something which is not often mentioned is that the level of training for the military has been improved over the last few decades. This does not only apply to officers, but also to soldiers who have civilian professional qualifications. ${ }^{9}$ One has to understand that the intelligence community is far wider than military intelligence, and one has to use all sources for intelligence there are. In quantitative terms, the amount of information available has increased over time, to a large extent made possible by technology. It is important at this point to clearly differentiate between the task of merely identifying targets and qualitative intelligence work. ${ }^{10}$ For this reason, scientific methods and theories must be used to a much greater degree

\footnotetext{
${ }^{8}$ HUMINT can mean different things in different contexts, see Ferris (2004, pp. 59 and 67) (Intelligence Operations).

${ }^{9}$ Ample opportunity exists to raise the level of education for soldiers at all levels in the future, by integrating university education (in this case in municipal adult education). This author will present thoughts on this subject on another occasion.

${ }^{10}$ Ferris $(2004$, p. 57). The difference between target identification and intelligence is indicated, but not the need to define which agencies are involved.
} 
than before-it is no longer enough to just gather all relevant information and start off. All relevant information will amount to too much for it to be managed without using a feasible method and approach. ${ }^{11}$

One problem concerning method is being able to differentiate between actors employing violence who have a political agenda, from those whose use of violence serves no political purpose at all. It is important not to ignore the requirement to address the problems posed by the criminal elements without political agendas, but one must quickly understand that they are not interested in exchanging their violent tactics for mass meetings and printing presses-they are not interested in any peaceful political strategy. The problem is illustrated by the following example from Iraq in summer 2005:

The shootings became so frequent in Baghdad this summer that Horst [Brig. Gen. Stf. C. 3 Inf. Div.] started keeping his own count in a white spiral notebook he uses to record daily events. Between May and July, he said, he tracked at least a dozen shootings of civilians by contractors, in which six Iraqis were killed and three wounded. The bloodiest case came on May 12 in the neighborhood of New Baghdad. A contractor opened fire on an approaching car, which then veered into a crowd. Two days after the incident, American soldiers patrolling the same block were attacked with a roadside bomb. [- - - Horst declined to provide the name of the contractors whose employees were involved in the 12 shootings he documented in the Baghdad area. But he left no doubt that he believed the May 12 incident, in which three people were killed, led directly to the attack on his soldiers that came days later on the same block. "Do you think that's an insurgent action? Hell no," Horst said. "That's someone paying us back because their people got killed. And we had absolutely nothing to do with it. ${ }^{12}$

\footnotetext{
${ }^{11}$ Only recently has it been axiomatically maintained that all relevant and reliable source information should be used in historical research, and something which was established in the earlier part of the 1900s in Sweden by Professor Lauritz Weibull, who was particularly interested in method. He was, however, primarily interested in the Swedish Middle Ages where too much information was never a problem. Researchers who are interested in current times must learn to filter information in a systematic way.

12 http://www.washingtonpost.com/wp-dyn/content/article/2005/09/09/ AR2005090902136.html [Visited 170509].
} 
The quote illustrates several relevant factors, one of which is that there is a requirement for observers on the ground to identify who is who on the field. It requires an almost hermeneutic method of observation, which in turn means that observers must have a good pre-understanding of whether an observation will lead to any relevant conclusions. In addition, the quote shows that it is not always easy to tell the difference between actors with a political agenda from those who merely react in trigger response in revenge for an incident. However, that it is difficult to differentiate between the two does not under any circumstances mean that one should cease to maintain an analytical approach. Finally, the example shows what happens if one does not know one's own operational aims. The antithesis of field theory is to internalise an approach in which one indiscriminately escalates the spiral of violence; achieving peace in the foreseeable future will be quite out of the question with the approach outlined above. In addition, even if the insurgents can see the differences between different Americans in this case, they might refuse to act correspondingly.

This mind map of a social field (do notice the characteristic 4-fields) focus on the right part of the field (in the oval). It focuses on those who conduct politics with violent methods for different reasons. Many of the groups there are dependent on the rules of other fields than the political one (primarily the economic field).

The diagram above shows the need for a deeper identification process after one has identified the actors using violent tactics. The question to answer after initial identification is the ever relevant why. Why do they have an agenda that involves violence? Only after these why-questions have been answered will it be possible to formulate a practical, purposeful course of action to engage these actors-and also those who already have an acceptable agenda. The engagement can be directly on the actors or towards structures on the social field which one estimates would affect these actors. Once again, it is more rewarding to act on changing the social field than aiming at certain actors directly, as it is not sure or even likely that you have identified all the actors you want to target. It is important to remember this, even if this discussion to a large extent deals with the actors. Aiming at the social structures will in its turn affect even actors you still don't know about. In the end, it is humans and their behaviour you want to see a change in, but the road might have to go through structural change first. 


\section{employing violence}

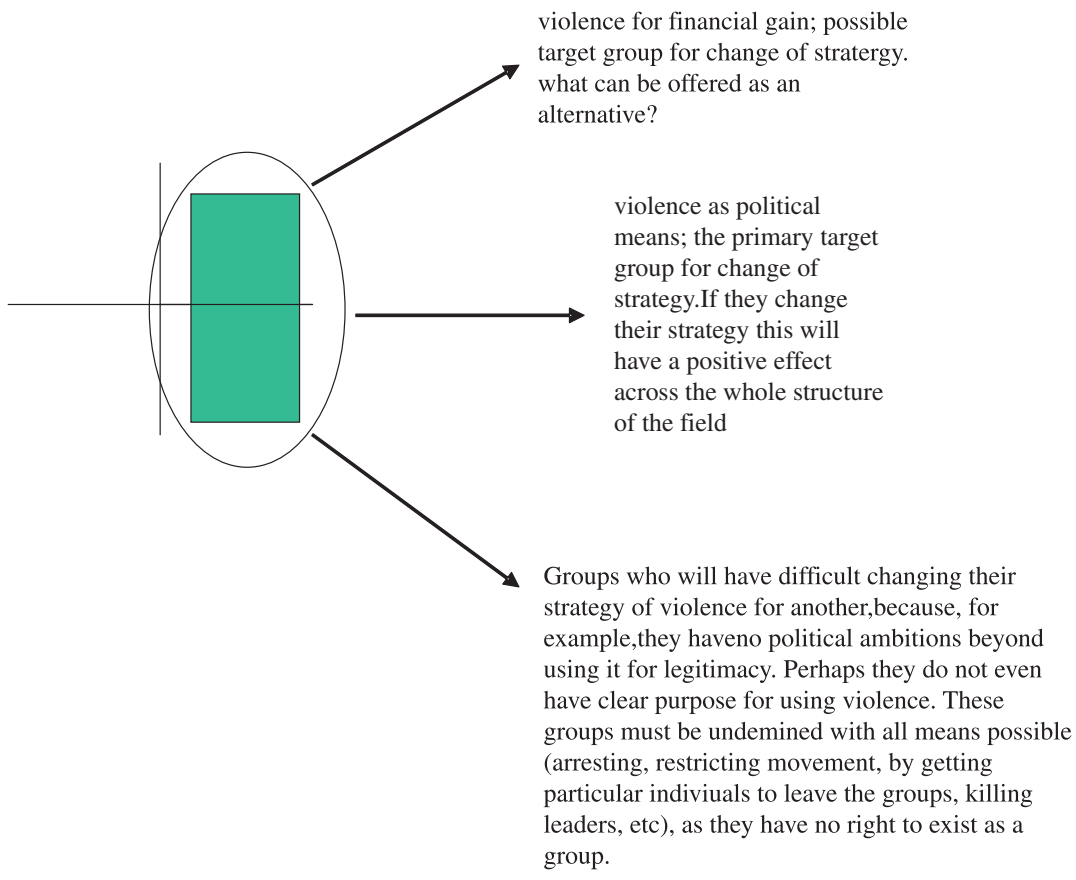

Fig. 4.1 Mind map dealing with violent actors

All actors, certainly not the collective ones, can easily be divided into just one of the social categories constructed (e.g. as in Fig. 4.1). One can imagine a group of people who had all three categories shown above represented organically. But as with all theory, the analyst must draw a good-enough line somewhere. As it might be a matter of life and death in this case, there is a need to communicate the perception of the actors to the actors, if one wants to affect their logic of practice.

Purposeful action means the military force adopts a course of action aimed at getting the actors to voluntarily change their strategy, involving methods beyond the purely firefighting techniques employed to prevent genocide and the like. A group that has no political agenda linked to its use of violence is difficult to influence using methods aimed at getting them to change from their current pattern of behaviour to acting 
peacefully in the political arena. In this case, it might involve actors who exercise force in the operations area and who thereby make financial gain through smuggling. The exercise of force is an outward manifestation of maintaining control over a smuggling operation. These actors are more interested in economic power than political power and should be tackled accordingly. This knowledge is of course important to enable an understanding of the actors and motives driving the current wave of violence in the operations area. David Kilcullen writes that in Afghanistan 30004000 of the Taliban (which were approximately $10 \%$ of them) were "hard-core fanatics who are not reconcilable under any circumstances". ${ }^{13}$ It is important to use not only physical violence, but foremost symbolic violence on these individuals. This can be discrediting them in religious, social, political, ethnic or economic ways. It is either this or giving up the idea that there is a cultural element in conflict, which there often is. That we, the West, for example, want to impose democracy on "the others" as that is something the West as a society believes to be objectively right like a jihadist believes in Islamic law as objectively right. Some people are hard to reach and that must be acknowledged as a fact and treated accordingly, with force if necessary.

Another method problem is the purely operational one of establishing collaboration between the military units and the various forms of voluntary organisations (NGOs). The latter often have a policy not to collaborate with military units. However, this problem lies outside the scope of the possible for a study of this nature; it will require a favourably pragmatic approach to operations in the field.

By way of introduction, it should be said that ethnic cleansing and genocide do not occur in all conflict situations. No matter what International law says; there are plenty of examples of people being forced to flee an area, or being killed just because of ethnicity and not because of some kind of actions taken on the victim's behalf. There is no shortage of plight and suffering among those who find themselves with the "wrong" ethnicity or nationality. This text is concerned with operational realities for forces on the ground, rather than definitions made for political reasons. International law is only normative if there are interests from important national states-which often can be condensed down to the USA, Russia or ex-colonial states in the region-so if an event

\footnotetext{
${ }^{13}$ Kilcullen (2009, p. 49).
} 
is called ethnic cleansing or not by International law is to a large extent politics. This does of course not stop experts in International law from having opinions that differ from what the world community decides is ethnic cleansing or not. At least ethnic cleansing has, however, proved to be a common element of the low-intensity conflicts waged since the Cold War. The process follows a relatively linear course and the breaking point may be said to illustrate a case of "external shock". ${ }^{14}$ It is then that the legitimacy of current norms is questioned in practice and not just in rhetoric. The reasoning also pre-supposes that explanatory models, such as Christopher Browning's in Ordinary Men: Reserve Police Battalion 101 and the Final Solution in Poland, are valid. Namely, that perceived conditions are of decisive importance, if not of sole importance, as a precursor to genocide. ${ }^{15}$ In the case of Yugoslavia, the process took place sequentially in a number of stages seen as separate outbreaks of the fighting. The fighting in Eastern Slavonia is an example of comprehensive state-controlled ethnic cleansing. This same type of phase occurred in the opening stages in Bosnia when the Bosnian Serbs enjoyed their initial successes. The expelling of, for example, the Kosovo Albanians from Kosovo may be seen as another key phase in the complicated course of events in Yugoslavia. This purge was conducted by special units, like Arkan's Tigers_led by Željko "Arkan” Ražnatović-who initially demonstrated a marked capacity for violent and spectacular action. ${ }^{16}$ Some think that it took until 2002 for the logic of ethnic cleansing just to begin to erode, but still not to be reversed. ${ }^{17}$

When the method for analysis has been chosen-quantitative or qualitative as discussed above-the next question to address is which method will be used to start influencing the field. In short, it would be fair to say that the method chosen will be a mix of the alternatives positioned between targeting and hearts and minds. The former involves getting to the actors one wants to influence, by either providing incentives or

\footnotetext{
${ }^{14}$ Farrell $(2005$, p. 14).

${ }^{15}$ Browning (1998, p. 173).

${ }^{16}$ The fact the Arkan's Tigers had a film team with them on at least one occasion strengthens the theory that their mission was to create conditions for a war of ethnic character, de Graaff (2003, p. 118). See also Allin (2002, p. 59).

${ }^{17}$ Allin (2002, p. 44). See Sell (2002). for more about paramilitary forces at the opening stages of the war, p. 165.
} 
limiting their room for manoeuvre (which in extreme cases may mean killing someone, a fact one should not turn a blind eye to when military operations are involved). The latter involves altering the structure of the field so that certain patterns of behaviour become unacceptable in the social field of the area of operations. In reality, it rarely involves a narrow focus on either actors or structures, but a blend of alternative courses of action.

As an epilogue, it is fair to mention that some actors are multifacetted and might have different appearances at the same time. One has to choose how to act with caution. An actor like PIRA, for example, could choose to use Sinn Fein, the political arm of the movement if the military tactics were less suitable at a certain time, only to shift to the military focus later on. The same goes with Hamas and Hezbollah, for example, they too can act on different parts of the social field depending on the circumstances. This does not make the model less suitable, it is very suitable in order to identify how these actors behave and why.

\section{BIBLIOGRAPHY}

Allin, D. H. (2002). Nato's Balkan interventions. Oxford: Routledge.

Bowyer, R. (1999). Dictionary of military terms. London: Bloomsbury Reference.

Browning, C. R. (1998). Helt vanliga män: Reservpolisbataljon 101 och den shtliga lösningen $i$ Polen. Stockholm: Norstedts.

Eckstein, H. (1965). On the etiology of internal wars. History and Theory, 4, 2.

Farrell, T. (2005). The norms of war: Cultural belief and modern conflict. Boulder: Lynne Rienner.

Ferris, J. (2004). Netcentric warfare, C4ISR and information operations. In L. V. Scott \& P. D. Jackson (Eds.), Understanding intelligence in the twenty-first century. journeys in shadows. London: Routledge.

Graaff de, B. (2003). The wars in former Yugoslavia in the 1990s: Bringing the state back in. In J. Ångström \& I. Duyvesteyn (Eds.), The nature of Modern War: Clausewitz and His critics revisited. Stockholm: Swedish National Defence College.

Kalyvas, S. N. (2009). The logic of violence in Civil War. Cambridge: Cambridge University Press.

Kilcullen, D. (2009). The accidental guerrilla. Fighting small wars in the midst of a big one. Oxford: Oxford University Press.

Sell, L. (2002). Slobodan Milošević and the destruction of Yugoslavia. Durham: Duke University Press. 
Open Access This chapter is licensed under the terms of the Creative Commons Attribution 4.0 International License (http://creativecommons.org/licenses/ by $/ 4.0 /$ ), which permits use, sharing, adaptation, distribution and reproduction in any medium or format, as long as you give appropriate credit to the original author(s) and the source, provide a link to the Creative Commons license and indicate if changes were made.

The images or other third party material in this chapter are included in the chapter's Creative Commons license, unless indicated otherwise in a credit line to the material. If material is not included in the chapter's Creative Commons license and your intended use is not permitted by statutory regulation or exceeds the permitted use, you will need to obtain permission directly from the copyright holder.

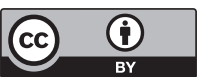

